\title{
GOING MOBILE:
}

\section{SUBSTITUTABILITY BETWEEN FIXED AND MOBILE ACCESS ${ }^{I}$}

\author{
Mark Rodini \\ Michael R. Ward \\ Glenn A. Woroch ${ }^{2}$
}

December 2002

\begin{abstract}
We empirically estimate the substitutability of fixed and mobile services for telecommunications access using a large, U.S. household survey conducted over the period 2000-2001. Estimated cross-price elasticities confirm that second fixed line and mobile services are substitutes for one another. The extent of fixed-mobile substitution has important implications for policy toward fixed network unbundling, fixed-mobile vertical separation, and universal service.

KEYWORDS: Telecommunications, Access, Mobile, Demand, Substitution

CORRESPONDING AUTHOR:

Michael R. Ward

Department of Economics

University of Texas at Arlington

330 Business Building

Box 19479 - UTA

Arlington, TX 76013

email: mikeward@uta.edu
\end{abstract}

\footnotetext{
${ }^{1}$ Prepared for the Conference on "Competition in Wireless: Spectrum, Service and Technology Wars," organized by the Public Utility Research Center at the University of Florida, Gainesville, February 2002.

${ }^{2}$ Rodini is a Graduate Student at the University of California, Berkeley, Ward is an Associate Professor at the University of Illinois and a Visiting Associate Professor at the University of Texas at Arlington, and Woroch is Adjunct Professor of Economics at the University of California, Berkeley. We are grateful to TNS Telecoms for generously sharing the Bill Harvesting data and providing technical assistance. This paper has benefited greatly from the research assistance of Fariza Ahmad at the University of Illinois. Both Ahmad and Rodini received financial support from the Center for Research on Telecommunications Policy of the Haas Business School, University of California, Berkeley. We are grateful to Mark Jamison and an anonymous referee for their comments on an earlier draft.
} 


\section{INTRODUCTION}

The spectacular growth of mobile phone service is well documented, with mobile users now exceeding one billion worldwide. ${ }^{3}$ By any measure, mobile service has reached rough parity with fixed line service in most regions, and surpasses traditional fixed-line penetration in developed and developing countries alike. Yet fixed lines have not been significantly displaced. While the total number of fixed lines has been flat in recent years, with net contraction in selected pockets, supplemental fixed lines continue to grow fueled by Internet and other data access needs. Overall, significant changes in the composition of households' access portfolios have taken place.

These developments invite analysis of the substitutability of fixed and mobile services as a means of access. The two services provide many of the same basic functions (dialtone, phone number, long distance access), and their price levels and structures have converged over time. Important differences between the two remain, however, with wireless service distinguished by its mobility and fixed service boasting superior transmission quality and bandwidth.

This paper provides empirical evidence of the degree of substitution between fixed and mobile telephone services. We employ a data set constructed from a U.S. consumer panel that contains detailed information on households' communications purchase behavior. These data, reported over a two-year period, include information about a household's subscription to fixed and mobile telephone service as well as usage of those and other communications services. Since the data set does not provide fixed and mobile prices, we develop a two-stage estimator of expected prices for access and usage of each service. We then determine how consumers' subscription decisions vary with the (estimated) mobile and second fixed line prices to calculate own- and cross-price elasticities of demand.

${ }^{3}$ ITU (2002). 
In general, we find that mobile access demand is elastic with respect to its own prices when compared to the range of typical elasticity estimates for fixed line service. We also confirm previous research that households' subscription to second fixed lines are much more price elastic than primary lines. Estimated cross-price elasticities confirm that second fixed lines and mobile service are access substitutes. In particular, we find a significant response in mobile subscription to fixed line rates.

These results can inform the regulatory debate over local telephone service competition. ${ }^{4}$ Increasingly, U.S. telecommunications policy has moved away from direct government oversight of firms' pricing decisions to greater reliance on competitive forces. A finding that mobile service offers a close substitute for fixed service would serve to undermine the rationale for regulation of fixed local services, and would bolster efforts to expand wireless alternatives, possibly by relaxing spectrum caps. Requirements of interconnection and unbundling of incumbent networks that represent the heart of the 1996 Telecommunications Act become less justified, and possibly harmful, when a viable, facilities-based alternative such as wireless mobile constrains fixed network providers. A close substitute for fixed service would also bring into question the need for safeguards against various kinds of anti-competitive conduct. The rationale for structural or functional separation aimed at preventing "discriminatory dealing" between fixed and mobile divisions of an integrated carrier begin to fade. ${ }^{5}$ Moreover, when consumers subscribe to mobile service in place of fixed access, subsidies paid only to fixed-line carriers to promote universal service are unjustified. In general, support targeted exclusively toward fixed-line penetration may not be furthering the goal of increased connectivity.

This paper is the first to our knowledge that examines fixed-mobile access substitution using household level data. The data also permit us to examine patterns over time to some

\footnotetext{
${ }^{4}$ For a more detailed discussion of fixed-mobile competition and its policy implications, see Woroch (2002).

${ }^{5}$ See Mini (2001) and Reiffen, Schumann, and Ward (2000).
} 
extent. Our approach to estimating prices of the two services appears to be novel yet appropriate to the empirical questions we seek to answer.

\section{BACKGROUND ON FIXED-MOBILE SUBSTITUTION}

Historically, mobile telephone service did not pose an attractive alternative to fixed service. Given its high relative price, cellular service was truly a luxury, not a substitute for fixed line. Cellular technology also lagged significantly in nonprice terms: transmission quality and geographic coverage were poor by fixed-line standards; early cell phones were cumbersome and not at all portable. These differences resulted in cellular's limited penetration rates when first introduced in the 1980 s. Since those early days, mobile service adoption has grown at astonishing rates as the quality of the service and the performance of mobile providers steadily improved.

The spread of mobile services comes at a time when telecommunications authorities and the public are concerned over the lack of speed in the development of competition in local services. Unbundling and resale of network services to facilitate entry has not produced the competition originally envisioned by legislation such as the 1996 Telecommunications Act in the U.S. Nor have competitive carriers overbuilt incumbent networks to any great extent. While large business customers in dense city centers may be able to choose between providers, most smaller businesses and residents have few facilities-based options available. The slower-thananticipated pace at which fixed-line incumbents have relinquished market share to competitors leaves mobile services as their most immediate and potent competition.

The promise of fixed-mobile competition turns, in part, on whether, under prevailing market demand and cost conditions, mobile alternatives prevent fixed-line carriers from exercising market power. As costs of mobile telephony continue to drop, allowing prices to fall and quality to rise, mobile becomes an increasingly attractive alternative to fixed-line service. Technically, mobile is a substitute because users can place and receive voice calls just as they do 
with fixed service. The relevant questions are whether consumers shift minutes from their fixed line(s) to their mobile phones, and whether they meet their expanding access needs with mobile lines or even disconnect their fixed lines and replace them with mobile phones.

So far, the incidence of users who forgo fixed service entirely and depend completely on mobile, are few in number. The profile of the typical wireless-only user is young and single. In its last two annual reports on the wireless industry, the FCC concluded from its review of thirdparty research that about $3 \%$ of U.S. users rely on mobile as their only phone service, while about $12 \%$ reported that they purchased mobile service rather than adding a supplementary fixed line. ${ }^{6}$ Two recent surveys of British residential consumers, conducted a year apart, both found that $5-6 \%$ of individuals claim mobile as their only source of telephone service in their home. ${ }^{7}$

An alternative view is that fixed and mobile services are complementary. Mobile service enables calls that were otherwise impossible, as when a user is traveling in a car or walking on the street. These and other mobile calls typically originate or terminate on a fixed line, so that mobile usage could stimulate fixed-line usage. ${ }^{8}$ Also, even new calling that never leaves the mobile network could nevertheless trigger return calls from fixed lines that otherwise might not occur. $^{9}$

The academic literature containing econometric analysis of the demand for mobile communications is limited. Most of the contributions rely on data aggregated to the metropolitan or country level. Hausman $(1999,2000)$ estimates the elasticity of aggregate subscription to cellular service in the 30 largest U.S. markets over the period 1988-1993. Ahn

\footnotetext{
${ }^{6}$ FCC $(2001,2002 c)$

${ }^{7}$ Oftel $(2001,2002)$.

${ }^{8}$ A household may make calls between its home fixed line and mobile phones carried by members while away from home.

${ }^{9}$ See Taylor (2002).
} 
and Lee (1999) estimate demand for mobile access in Korea using more recent wireless subscription data for 64 countries.

Only recently has research appeared that examines fixed-mobile substitution. Sung, Kim and Lee (2000) find that the number of Korean mobile subscribers is positively correlated with the number of fixed-line disconnects, but negatively related to the number of new fixed-line connections, suggesting net substitution between the two services. This pattern occurs even while the stock of fixed lines is positively correlated with the number of mobile subscribers, offering evidence that the two services are complements. ${ }^{10}$

A more recent, and in some ways a more developed, body of work exists on demand for secondary fixed lines. Eisner and Waldon (2001) and Duffy-Deno (2001) examine the determinants of household subscription to supplemental fixed lines in the U.S. in the late 1990s. In an earlier study, Solvason (1997) used a 1994 Canadian household survey to estimate the choice among three options: no fixed service, a single line and multiple lines. All of these investigations were made possible only with access to large, detailed household surveys that recorded the number of fixed lines as well as individual demographic information.

\section{MODELING HOUSEHOLD ACCESS AND USAGE DECISIONS}

The decision to subscribe to fixed and mobile services is part of a larger telecommunications consumption problem. To model this problem, we take the household as the decision maker. ${ }^{11}$ Given various prices and income, the household chooses a portfolio of the two kinds of lines, and then chooses how much of each line to use so as to maximize household

\footnotetext{
${ }^{10}$ Ahn and Lee (1999) also find evidence of complementarity also using aggregate data.

${ }^{11}$ While mobile telephony is a single-user technology, whether to subscribe to a mobile service is likely to be part of a household's overall budgeting problem. Note also that answers given by survey respondents may not represent accurately the preferences of the entire household or the household's designated decision maker-a weakness of the survey procedure used to collect information in our data set.
} 
utility. ${ }^{12}$ When evaluating portfolios of lines, households derive value from the connectivity and mobility they offer. Connectivity refers to the two-way bandwidth made possible by the line. Mobility is gauged by the size of the region over which dial tone is available, as well as the ground speed at which the connection can be maintained.

Utility derived from subscription to either service derives from the use of the service. We do not separately model the usage decision, but rather include usage prices in the reduced form demand for access. Motivation for this specification was first given in the context of a logit model by Perl (1978).

We follow the standard demand specification for subscription decisions in which demand for these goods depends on their own price, the prices of substitutes and complements, and on household income, plus attributes of the household and the characteristics of the various alternatives. Mobile subscription usually involves a monthly charge, possibly over the contract period that may run a year or two. ${ }^{13}$ Mobile usage is charged by the minute, or some fraction thereof, with additional usage-sensitive charges for long distance and international service and when the user is "roaming" outside her home calling area. These usage fees depend crucially on the boundaries dividing the home zone and the roaming region.

A complication of mobile pricing (and fixed service as well) that raises empirical issues is that users select from a menu of calling plans, each one with a different monthly charge, a different amount of included "free" minutes, and a different per-minute charge for usage exceeding the allowance. Furthermore, mobile prices vary across providers within each market,

\footnotetext{
${ }^{12}$ See Taylor (1994) for a review of related studies modeling both of subscription and usage decisions.

${ }^{13}$ Ideally, subscription to either service will include one-time expenditures required to initiate service. Fixed service involves a "connection fee" and mobile service an "activation fee." Both will require some investment in terminal equipment. Even prepaid mobile service which eliminates subscription fees altogether requires a handset.
} 
and similarly for fixed-line services as residential competition emerges. ${ }^{14}$ To simplify, we assume that consumers make their choice of calling plan based on their expected calling volume for both services in their respective market. The challenge is to summarize "the price" of mobile service along a single dimension..

Summarizing prices as a single access and per-minute usage price oversimplifies much more complex pricing schedules. Ideally, one would want data on the price plan details to which the household has subscribed, in addition to the set of alternatives available at the time of the subscription decision. Without this, an alternative approach might be an attempt to derive a set of two-part tariffs that would vary by household usage "type." Miravete (2002b) assumes such a structure in determining how a monopoly supplier should design its pricing schedule. Miravete also argues that, at any point in time, subscribers should not be expected to be consuming at the optimum for the plan they chose ex ante; that is, exactly on the lower envelope of a continuum of two-part tariffs. Our approach is consistent with this, and assumes that while the correct plan was chosen, the optimum usage may not be observed on a particular bill, for a household, and out of computational convenience, we approximate the variation in household usage and expenditures as having derived from a single two-part tariff. Clearly, a more detailed treatment of the pricing complexity would be preferable.

It is probable that non-price quality improvements, rather than price reductions, played a major role in the increase in mobile adoption rates. Non-price characteristics of mobile services can vary considerably, and they should be taken into account. Coverage area has always been a critical aspect of mobile service-in the early days when the networks were first built, as well as

\footnotetext{
${ }^{14}$ We also do not take account of bundled vertical services (e.g., call waiting, voice mail) which vary across plans, or of bundled minutes which vary by peak and off-peak periods. One discrepancy stems from the fact that, in the U.S., both incoming and outgoing mobile calls are charged, or at least deducted against any usage allowance, whereas only outgoing calls are priced for fixed line service. Consequently, relative price of mobile service will tend to be underestimated because fixed line usage is underestimated. This bias will tend to disappear as mobile service moves to flat rates. One additional discrepancy would arise if a user's employer paid for all or part of a respondent's fixed or mobile bill. We believe that it is unlikely that a household will submit a bill in response to the survey if this were the case.
} 
today in terms of digitalization and $3 \mathrm{G}$ capabilities. Moreover, local areas exist where calling volume demanded currently is beyond the capacity of the infrastructure or where transmission is obstructed. These "hot spots" and "dead zones" are largely determined by the number and placement of base stations. In addition, with new digital transmission and signaling technologies, the feature set of mobile phones has expanded considerably, the size and weight of the handset has fallen, and the battery life has been extended.

As mentioned above, the price and availability of fixed-line alternatives will condition mobile demand. Besides basic local and long distance services, a household may have the choice to use a work phone (for both voice and Internet), cable telephony, or considerably less often, fixed wireless access. Options that specifically deliver some degree of mobility are paging services and public payphones.

Increasingly, demand for data transmission is driving individuals' access and usage choices. Today, dial-up access over traditional phone lines is the predominant means to access the Internet. Often a household will dedicate a second fixed line for this purpose. ${ }^{15}$ The introduction of high-speed access, especially digital subscriber line (DSL) and cable modem services, however, likely reduces the demand for these lines.

Demographic characteristics of a household likely play a role in determining its communication needs. The number and age distribution of household members, their education levels, employment status and occupations all may be important. Women, for example, mention security as an important reason for subscribing to mobile services even if they rarely use it. One would also expect that individuals who telecommute or run a business from home would have higher demand for fixed-line service. In contrast, workers who face long commute times are predisposed to subscribe to mobile service.

\footnotetext{
${ }^{15}$ Connection to a facsimile machine is another motivation for a second fixed line that is increasingly less common.
} 


\section{DATA DESCRIPTION}

The main source of data in our analysis are the Bill Harvesting data from TNS Telecoms ReQuest Market Monitor ${ }^{\circledR}$ along with its survey responses. ${ }^{16}$ This quarterly sample of U.S. household consumption of various telecommunications services is derived from a large national panel. Participating households are asked to submit one set each of their original bills for local, long distance, cable TV, cellular and Internet services. Besides summary information, the data set extracts detailed call information from each "harvested" phone bill. While these data were first collected in 1995, this paper uses data from the two-year period January 2000 - December 2001 during which a uniform sampling method and survey instrument were employed. While constructed from a subset of a panel, the Bill Harvesting data do not themselves constitute a panel. ${ }^{17}$ Finally, household demographic information was also collected as well as responses from survey questions.

Table 1 provides overall summary statistics for the 2000-2001 ReQuest ${ }^{\circledR}$ data. We limit our analysis to the 294 urban areas in the U.S. for which we have topographical and population data we use to determine prices below, but report summary statistics for the complete sample as well.

Figure 1 depicts the subscription to mobile service, pagers and second fixed lines derived from the ReQuest survey over this period. The percentage of households with mobile service increased from just under $45 \%$ in 2000 up to over $56 \%$ in 2001 , while second fixed line subscriptions remained flat and pager use fell on net. These figures match closely the growth rates reported by the CTIA (2002) and by other nationwide data sources.

Figure 2 plots responses from a ReQuest survey question asking mobile subscribers why they subscribed to mobile service. While the fraction of the population that indicates that it was

\footnotetext{
${ }^{16}$ See $<$ www.tnstelecoms.com $>$.

${ }^{17}$ About a quarter of all survey respondents actually submitted their phone bills, and of these households, about $10 \%$ were re-sampled during the 2000-2001 period.
} 
at the expense of fixed service increases over time (rising from $7.1 \%$ to $11.2 \%$ ), that fraction remains quite small and is consistent with data reported by the FCC for the U.S. and by OFTEL for the U.K.

While the data set contains access fee and usage charge breakdowns, these are drawn only from what is explicitly recorded on the bill. The Bill Harvesting data set includes neither prices of the subscribed services, nor prices for services not chosen. Moreover, since bills do not indicate the commencement date of the service, and because companies differ in their billing conventions, it is not possible to back out the ex ante subscription and usage charges that households face when making their subscription and usage decisions. This is true for fixed service as well as for mobile. ${ }^{18}$

Below, we spell out how expected marginal prices for these services can be estimated from the information contained in the bills. This is done for both fixed and mobile services.

\section{SPECIFICATION}

\section{A. Fixed and Mobile Access and Usage Prices}

Our primary goal is to estimate the degree to which consumers' decisions to subscribe to mobile service and supplementary fixed lines are determined by the prices of both services. Pricing of the two services - especially mobile service - tend to be highly complex, with carriers offering multiple calling plans with non-uniform prices that vary over time and across region. Furthermore, many households will have subscribed to either service sometime in the past under a rate plan that may not even be available to new subscribers during the sample period.

The enormous complexity of the pricing options available to households in an area necessitates that we simplify. For this reason, we estimate prices using the empirical relationship between fixed and mobile bills and the observed usage levels of each service. We

\footnotetext{
${ }^{18}$ Some of the earliest local access demand studies controlled for the availability of flat and measured service to a household. See Perl (1978).
} 
specify a random coefficients regression to estimate a representative two-part tariff for each geographic region, where fixed-line prices vary by state and mobile prices vary by cellular franchise area. ${ }^{19}$

For mobile service, we regress the amount of the monthly bill submitted by households (after deducting equipment, features and associated tax charges) on a set of shifters, $z_{j k}$, that likely affect pricing across regions, as well as on these same measures interacted with the minutes of use reported on the bill:

$$
\text { Bill }_{i}=\sum_{k}\left(\alpha_{k}+\varepsilon_{k}\right) z_{j k}+\sum_{k}\left(\delta_{k}+\mu_{k}\right) z_{j k} \times \text { Minutes }_{i}
$$

where $i$ indexes the household, $j$ indexes the geographic area where household $i$ resides, and $k$ indexes the shifter. We have included additive random error terms, $\varepsilon_{k}$ and $\mu_{k}$, on the coefficients, $\alpha_{k}$ and $\delta_{k}$, resulting in a random coefficients specification. ${ }^{20}$ The dependent variable is the observed bill net of equipment and features charges. ${ }^{21}$ The shifters include many direct and indirect measures of cost of building and operating mobile phone systems in a geographic area, as well as a constant term and a time trend.

Using the estimated regression coefficients, we take as the access and usage prices in market $j$ the fitted values for the intercept and slope of the regression in (1):

$$
P_{A j}^{s}=\sum \hat{\alpha}_{k} z_{j k} \quad P_{U j}^{s}=\sum \hat{\delta}_{k} z_{j k}
$$

where $s=f$ and $s=m$ refer to fixed and mobile service, respectively. A different set of prices is calculated for both 2000 and 2001 to be used in separate demand specifications for each year.

\footnotetext{
${ }^{19}$ Cellular Franchise Areas, also known as the Mobile Service Areas and Rural Service Areas are geographic delineations assigned by the FCC to award mobile service licenses. We limit our analysis to the largest 294 Mobile Service Areas that were designed to roughly correspond with Census SMSAs.

${ }^{20} \mathrm{We}$ presume that these errors have mean zero and are uncorrelated with the regression error.

${ }^{21}$ Households with excessively large bills relative to recorded minutes were dropped from the wireless price estimation, but as with fixed line, were assigned estimated prices corresponding to their region of residence for demand estimation.
} 
For fixed line prices, we follow the same basic approach as with mobile prices, with some exceptions. First, since bill data exists for access and usage separately, we estimate access and usage components in (1) separately. The difficulty of disentangling usage charges from access on wireless bills for a large number of observations prohibits estimating wireless access and usage separately. Second, we replace the set of shifters, $z_{j k}$, with state dummy variables corresponding to the residence of the subscriber. The state dummies reflects continuing statelevel regulatory oversight of fixed local access and local toll prices. ${ }^{22}$ Thus, we assume all households in state $k$ face the same fixed-line access and local toll usage prices. ${ }^{23}$

For mobile prices, we include continuous supply variables that vary across geographic markets. We chose this approach instead of simply using regional dummy variables for several reasons. First, since mobile retail prices are not regulated, they are more likely to reflect supplyside factors other than regulatory differences. Second, data are available by cellular franchise area that proxy for cost differences. Third, with fewer observed mobile subscribers and more geographic areas, we observe relatively few household bills in some geographic markets. In this case, it is more likely that idiosyncratic household usage patterns for an outlier will affect estimated prices than underlying cost differences as measured by the dummy variable approach. A summary of these variables and their sources is reported in Table 2 .

The choice of using supply-side measures to estimate mobile prices reflects the problem of endogeneity of prices in the main demand estimation. Actual price variability will reflect both demand and supply factors. Thus, to identify exogenous supply prices from consumers'

\footnotetext{
${ }^{22}$ I some cases fixed local prices vary within a state but we believe that this variation is minimal compared to other potential sources of measurement error, such as the unobserved choice of local calling plans. Furthermore, intrastate differences are usually due to partitioning the state between an RBOC and an independent. Since RBOCs dominate large metropolitan areas, and since our analysis is limited to urban areas, we believe that state dummy variables adequately capture the main sources of variation.

Secondly, it is debatable whether fixed local prices reflect actual costs of provision. We take the position that the primary determinants of price vary at the state-level, usually based on cost or regulatory conditions. Therefore, state dummy variables should adequately capture cross-sectional price differences. We thank an anonymous referee for raising this issue.

${ }^{23}$ Household with reported negative access fees were dropped from the fixed line regressions, although they were assigned prices corresponding to their state of residence for access demand estimation.
} 
willingness to pay, we predict prices using $z_{j k}$ variables that are correlated with them, but that are likely uncorrelated with household-level demand determinants.

Variables included in the $z_{j k}$ matrix include five land topography indicators, ranging from areas characterized as "flat plains" to "mountainous," where costs would be expected to be higher due to the need for more cell towers. Additional cost determinants we include are the population density, a measure of average marginal tax rates, and the number of months a cellular market has been in operation. Other included variables that affect the suppliers' prices are the number of mobile providers in the market, a measure of industry concentration (i.e., HHI), and a survey measure of perceived cellular quality. The regional industry structure variables reflect competitive pricing pressures, and the quality measure, derived as geographic market averages of wireless service satisfaction rating of households, reflects the cost of providing quality service. $^{24}$

Though not included in the $z_{j k}$ matrix, we add a third component to (1) in the estimation of wireless prices by including indicator variables for heavy mobile use households to control for possible additional promotional discounts to new subscribers that may be present, but unobservable, in the bill. Thus, the non-variable component of the predicted mobile access fee -the fitted coefficient on the intercept- includes the influence of these potential rewards for choosing wireless access.

One concern with how we estimate prices is that they were based on observed bills rather than on the actual choices faced by consumers at the time of the access decision. ${ }^{25}$ In reality, mobile service plans typically include some amount of "free minutes" with a per-minute charge for each additional minute beyond the allowance. In this case, our estimate of the usage price

\footnotetext{
${ }^{24}$ Other factors driven by strategic concerns such as penetration pricing, and the desire to build a national footprint also affect wireless prices, and would be necessary components of a structural model of wireless price setting. Yet, while we do include some structural measures that could proxy for strategic response, we do not model price setting behavior of fixed and mobile providers. Our main requirement is to identify cross-sectional price variation independent from factors that affect demand at the household level.

${ }^{25}$ Unfortunately, besides the fact that we do not observe the actual choices households faced, we also cannot observe the date of initial subscription.
} 
derives from two margins. The first is the ex post probability that a household exceeds its "free minutes" times the per-minute fee for additional minutes. The second relates to a household's ex ante choice of calling plan. Typically, consumers can choose from a menu of plans that tend to offer greater usage allowance for a higher monthly access charge. The difference between the prices and the expected usage for two plans represents a shadow price of usage. Miravete (2002a) provides evidence that consumers typically make correct ex ante choices of calling plan when choosing between flat rate and measured local service, and that they learn from their mistakes. This implies that deriving the ex ante prices based on ex post observed expenditures leads to a fair approximation of the actual effective choice they faced in deciding between either wireless or a second fixed line.

An implication for the estimation of (1) for mobile prices is that the access decision was likely based on expected usage over the contract period which could differ from actual usage. As a result, so long as a customer does not exceed his "free minutes," actual usage is irrelevant to the bill amount. However, the bill amount will depend on the number of bundled "free minutes" which in turn depends on the expected calling volume. The implicit usage price is thus a function of consumers' expected minutes used. In addition, since minutes demanded are a function of mobile prices, endogeneity is likely to bias estimates of $\alpha$ and $\delta$. Therefore, we use a two-stage estimator, where minutes are first regressed against a set of variables related to customer calling volume. The resulting predicted number of minutes is both free of differences in supply conditions and represents the rationally expected calling volume conditional on the available demographic information. The projection of minutes on these demand shifters is then used as an instrumented value for Minutes $_{i}$ in (1). The demand shifters include the demographic variables listed in Table 1. 
We estimate (1) using least squares weighted by sample weights. ${ }^{26}$ Because the error structure allows for heteroskedasticity, the estimation also makes the Huber-White correction to the variance matrix. While the estimation exhibits is plagued by low predictive power common to cross-sectional analyses (R-squared values in the 0.30 to 0.36 range), F-tests always reject that the coefficients are not jointly statistically significant. Table 3 reports the averages of the estimated marginal prices for 2000 and 2001.

\section{B. Demand Specification for Secondary Fixed and Mobile Access}

We specify a household's decision whether to subscribe to a second fixed line or to mobile service using a binary logit model, estimated separately from the decision to subscribe to the other. The basic estimating equation for each service, $s=f$ or $s=m$, is as follows:

$$
\pi_{i}^{s}=\operatorname{Pr}\left[U_{i}(\text { subscribeto } s)>U_{i}(\text { not subscribeto } s)\right] \text {. }
$$

where $U_{i}$ represents household i's utility derived from an alternative. In this specification, the probability of household $i$ subscribing to service $s$ depends on the access and usage prices for both services, as well as on a matrix of household and market characteristics, $x_{i}$. A household will subscribe if the utility of subscription exceeds the utility of non-subscription. Under the logit specification, the probability of subscription is expressed as:

$$
\log \left[\left(1-\pi_{i}^{s}\right) / \pi_{i}^{s}\right]=\beta_{A m}^{s} P_{A i}^{m}+\beta_{U m}^{s} P_{U i}^{m}+\beta_{A f}^{s} P_{A i}^{f}+\beta_{U f}^{s} P_{U i}^{f}+\gamma^{s} x_{i}
$$

Note that although the logits specify the probability of choosing access, usage prices enter because, as previously discussed, the access choice is dependent on expected usage. The two logits we estimate--one for fixed service and one for mobile--could be stochastically dependent

\footnotetext{
${ }^{26}$ We used sample weights provided by TNS, Inc. that are based on age, income and location of residence, and are intended to make the survey data more representative of a random cross-section of U.S. households.
} 
through correlation in the error terms. Based on a check for this stochastic dependence, we treat the two decisions are independent below. ${ }^{27}$

The explanatory variables, $x_{i}$, include household income and size, the head of household's race, age, education, marital status and work habits, as well as the presence in the home of such additional services like Internet access and a fax machine. Table 1 lists the household-level controls included. Market-level controls include average daily commute times, average annual vehicle miles, and an average measure of self-reported quality of existing mobile and fixed-line service within a geographic area.

\section{ESTIMATION}

We estimate demand for each of two years: 2000 and 2001. Given the spectacular growth in mobile subscription and usage over this period, our presumption is that demand behavior may likely vary across the two years. With growth in subscriber base, we expect that new mobile subscribers will tend to be more price sensitive than those who have previously adopted the technology. At the same time, it is possible that continuing subscribers have incorporated mobile phone service more tightly into their daily routines and became more inelastic in the process. In the end we will find that, in most cases, average demand behavior does not change even while massive changes occur in the nature of the customer base.

\section{A. Mobile Access}

Averages of household elasticities that were computed using the mobile access logit estimations are given in Table $4{ }^{28}$ estimates of all the coefficients are reported in Table 5 . We find that the likelihood of a household subscribing to mobile service is decreasing in access

\footnotetext{
${ }^{27}$ We estimated a bivariate probit for the two subscription decisions on the same sample and found negligible impact on estimated elasticities, and a positive but small correlation between error terms of the two probits.

${ }^{28}$ Following Train (1986), we calculated these as the mean elasticity across consumers evaluated at their predicted probability of subscribing.
} 
charges for mobile service and increasing in fixed line access charges. We also find own-price elasticities of mobile access demand with respect to the monthly recurring charge of -0.43 for both years, that are both highly statistically significant. As is typical, usage elasticities are not consistently estimated. The overall elasticity of access and usage price increase is -0.60 for 2000, which falls in the range of other demand elasticities estimated using aggregate data from earlier time periods and other markets. ${ }^{29}$

The cross-price elasticity of fixed access price on mobile demand is positive and statistically significant: 0.18 for 2000 and 0.13 for 2001 , and again these are estimated with a high degree of precision. These results indicate that, all else held constant, consumers are more likely to subscribe to mobile service in areas with relatively higher fixed-line rates and/or relatively lower mobile rates. We conclude that mobile service is a substitute for fixed-line access, although this could be due to substitution out of secondary lines.

\section{B. Second Fixed Line Access}

We also estimate the demand for a second fixed line using the logit model described by (3). Average price elasticities for second fixed line subscription are reported in Table 7; detailed logit coefficient estimates can be found in Table 8. Table 7 shows that second fixed line subscription is fairly elastic with demand elasticities of -0.69 and -0.65 . Compared with previous elasticity estimates for the first fixed line, reported to be much less elastic than -0.10 , these results indicate that second lines are more own-price elastic, as would be expected. However, our second-line elasticity estimates are somewhat larger than estimates of own-price

\footnotetext{
${ }^{29}$ Hausman (1999) reports a price elasticity of subscription of -0.51 for cellular subscription in the 30 largest U.S. markets over the period 1988-93. Ahn and Lee (1999) estimate subscription as a function of average connection, recurring and usage changes using aggregate country-level data. While they do not report price elasticities, it is possible to infer probit own-price elasticity of the monthly recurring charge equal to -0.36 .
} 
elasticities for second fixed lines in studies found in the literature. ${ }^{30}$ We also find positive crosselastic effects from mobile prices of 0.26 to 0.22 , although these are not statistically significant at the usual confidence levels.

Our data are not rich enough to estimate the cross-elastic effect from wireless price changes on the decision to subscribe to any fixed line. Only about $1-2 \%$ of our sample does not subscribe to fixed line service. However, demand theory implies that the cross-elasticity from mobile price changes to fixed subscription is very likely to take on the same sign of the effect from fixed price changes to mobile subscription. ${ }^{31}$ By the Slutsky equation, budget-share weighted cross-price elasticities should be nearly equal,

$$
w_{i} \eta_{i j} \approx w_{j} \eta_{j i}
$$

We can use the cross-elasticity estimates from Table 7 and the ratio of average expenditures on mobile and fixed service ( 0.45 in 2000 , and 0.53 in 2001) to calculate the effect of mobile access price changes on fixed line access. Applying the symmetry condition yields a crosselasticity from mobile access price to fixed line subscription of about 0.06-0.08. As expected, this calculation, which theoretically applies to subscription to any fixed line service, yields a somewhat smaller estimated magnitude than that estimated specifically for secondary line service.

\section{Non-Price Factors}

Non-price factors that significantly increase the probability of subscription include

\footnotetext{
${ }^{30}$ Using earlier Bill Harvesting data, Duffy-Deno (2001) estimates an own-price elasticity for second lines of -0.59 using a binomial logit model. Relying on the same source for subscription data, Eisner and Waldon (2001) estimate a bivariate probit model of second fixed line and ISP subscription, and find an elasticity of -0.35. Employing a large household for Canada, Solvason (1997) estimates an elasticity of secondary line demand of -0.48 .

${ }^{31}$ See Deaton and Muelbauer (1980).
} 
income, age, race, female head of household, married households and household size. Table 6 reports the predicted probability of subscribing to mobile and second line service as a function of income, age, households size, and other household characteristics. Mobile subscription exhibits a strong positive income effect with subscription rates for members of highest income group almost $40 \%$ higher than the lowest group, a $90-140 \%$ increase. It is perhaps not surprising that younger consumers have been more willing to adopt this new technology. However, it is surprising that subscription probabilities of the oldest households are $13 \%-20 \%$ lower. Consistent with Eisner and Waldon's (2001) finding of relatively greater telecommunications demand by blacks, our results suggest that black households have $8 \%$ higher subscription rates. Consistent with the demand for security hypothesis, female headed households have $9 \%$ higher subscription rates. Variables related to the demand for intra-household calls, such as married and household size, tend to increase the likelihood of mobile subscription. Similarly, variables related to communications intensity of the household-such as personal computer, internet access, modem pager, fax machine, and working from home-all increase the probability of subscribing. ${ }^{32}$

As for mobile service, non-price factors such as income, age, race, household size, and education also affect the probability of secondary line subscription. Table 6 reports the percentage increase in the probability of subscribing to a secondary telephone line as a function of income and age. Income plays a somewhat smaller role in second line subscription than with mobile subscription with subscription rates for members of highest income group only $9 \%$ higher than the lowest group, a $65-75 \%$ increase. ${ }^{33}$ Second line subscription seems to peak among middle aged families, aged 45-65 with a household size of three or more. As expected, working from home and having a fax machines or Internet access has a strong positive effect on second line subscribership.

\footnotetext{
${ }_{32}$ While these variables tend to be highly, positively correlated, multicollinearity is not a problem as confirmed by the very low standard errors on these variables.

${ }^{33}$ See Taylor (1994).
} 


\section{CONCLUSIONS}

Substitutability between fixed and mobile telephone service impacts public policy toward competition in both of these markets. In the U.S., the principal concern over competition in these markets derives from the market power held by providers of fixed-line local telephone service. Our estimates indicate that mobile service is a moderate substitute for fixed-line access. Evolving usage patterns suggest that mobile and fixed service will become greater substitutes over time. It would be premature, however, to infer from these estimates that mobile service currently constrains local telephone service market power to any economically significant degree over the 2000-2001 period. But while impediments to easy substitution remain-especially connection quality and number portability-discrepancies between the two services are fading.

Substitutability may increase over time due to continued price declines and feature improvements of mobile services outpacing those of fixed service. A small but increasing number of households are opting for mobile service in lieu of fixed service. At some point in the near future, it is possible that mobile telephone service will be able to significantly constrain fixed line providers' exercise of market power. When this does occur, it will be appropriate to modify many of the current regulatory stances toward telecommunications provision. In the meantime, while mobile has displaced fixed service for a select subset of the population, the two services appear to have achieved a coexistence in the marketplace as well as in household budgeting, each providing consumers with particular advantages. 


\section{REFERENCES}

Ahn, Hyungtaik, and Myeong-ho Lee (1999) "An Econometric Analysis of the Demand for Access to Mobile Telephone Networks," Information Economics and Policy, 11, pp. 297305.

Cellular Telephone Industry Association (1991) "State and Local Taxation of Cellular Industry."

Cellular Telephone Industry Association (2002) "Semi-annual Mobile Telephone Industry Survey," CTIA: Washington, D.C., June $<$ http://www.wow-com.com/ $>$.

Deaton, Angus and John Muelbauer, Economics and Consumer Behavior, Cambridge University Press, New York, NY, 1980.

Duffy-Deno, Kevin (2001) "Demand for Additional Telephone Lines: An Empirical Note," Information Economics \& Policy, 13, pp. 283-299.

Eisner, James, and Tracy Waldon (2001) "The Demand for Bandwidth: Second Telephone Lines and On-Line Services," Information Economics \& Policy, 13, pp. 301-309.

Federal Communications Commission (2001) "Sixth Annual Report and Analysis of Competitive Market Conditions With Respect to Commercial Mobile Services," Wireless Competition Bureau, June 20, 2001.

Federal Communications Commission (2002a) "Trends in Telephone Service," Industry Analysis Division, Wireline Competition Bureau

Federal Communications Commission (2002b) "Local Telephone Competition: Status as of December 31, 2001," Industry Analysis Division, Wireline Competition Bureau, May 2002.

Federal Communications Commission (2002c) "Seventh Annual Report and Analysis of Competitive Market Conditions With Respect to Commercial Mobile Services," Wireless Competition Bureau, July 3, 2002.

Hausman, Jerry (1999) "Cellular Telephone, New Products and the CPI," Journal of Business and Economic Statistics, 1999.

Hausman, Jerry (2000) "Efficiency Effects on the U.S. Economy from Wireless Taxation," National Tax Journal, 2000.

International Telecommunications Union (2001) Yearbook of Statistics: Telecommunication Services, 1990-1999, Geneva.

Mini, Federico, "The Role of Incentives for Opening Monopoly Markets: Comparing GTE and BOC Cooperation with Local Entrants," Journal of Industrial Economics, v49, n3 (Sept. 2001): 379-414. 
Miravete, Eugenio (2002a) "Estimating Demand for Local Telephone Service with Asymmetric Information and Optional Calling Plans", The Review of Economic Studies, 69, pp. 943971.

Miravete, Eugenio (2002b) "Choosing the Wrong Calling Plan? Ignorance and Learning”, American Economic Review, forthcoming.

OFTEL (2001) "Consumers' use of mobile telephony: Summary of Oftel residential survey" (fifth wave of Oftel's quarterly residential consumer survey conducted in May 2001), July 2001.

OFTEL (2002) "Consumers' use of mobile telephony: Summary of Oftel residential survey" (seventh wave of Oftel's quarterly residential consumer survey conducted in November 2001), 29 January 2002.

Perl, Lew (1978) "Economic and Social Determinants of Residential Demand for Basic Telephone Service," National Economic Research Associates, White Plains, NY, March.

Reiffen, David, Laurence Schumann and Michael R. Ward, "Discriminatory Dealing with Downstream Competitors: Evidence from the Cellular Industry," Journal of Industrial Economics v48 n3 (Sept., 2000).

Solvason, D. Lynn (1997) "Cross-sectional Analysis of Residential Telephone Subscription in Canada using 1994 Data,” Information Economics \& Policy, 9, pp. 241-264.

Sung, Nakil, Chang-Gun Kim, and Yong-Hun Lee (2000) "Is POTS Dispensable? Substitution Effects Between Mobile and Fixed Telephones in Korea," paper presented at International Telecommunications Society biennial conference, Buenos Aires, July 2000.

Taylor, Lester (1994) Telecommunications Demand in Theory and Practice, Kluwer Academic Publishers: Dordrecht, The Netherlands.

Taylor, Lester (2002) "Demand Analysis," chapter in Handbook of Telecommunications Economics, edited by Martin Cave, Sumit Majumdar, and Ingo Vogelsang, Elsevier Publishing, 2002.

TNS Telecoms (1999-2001), "ReQuest Survey,"

Train, Kenneth (1986) Qualitative Choice Analysis: Theory, Econometrics and an Application to Automobile Demand, MIT Press: Cambridge.

U.S.D.A. (19-), Economic Research Services

U.S. Gazetteer Place and Zipcode Files (19-)

Woroch, Glenn (2002) "Local Network Competition," chapter in Handbook of Telecommunications Economics, edited by Martin Cave, Sumit Majumdar, and Ingo Vogelsang, Elsevier Publishing, 2002. 
Figure 1

\section{Percent of Households with Service}

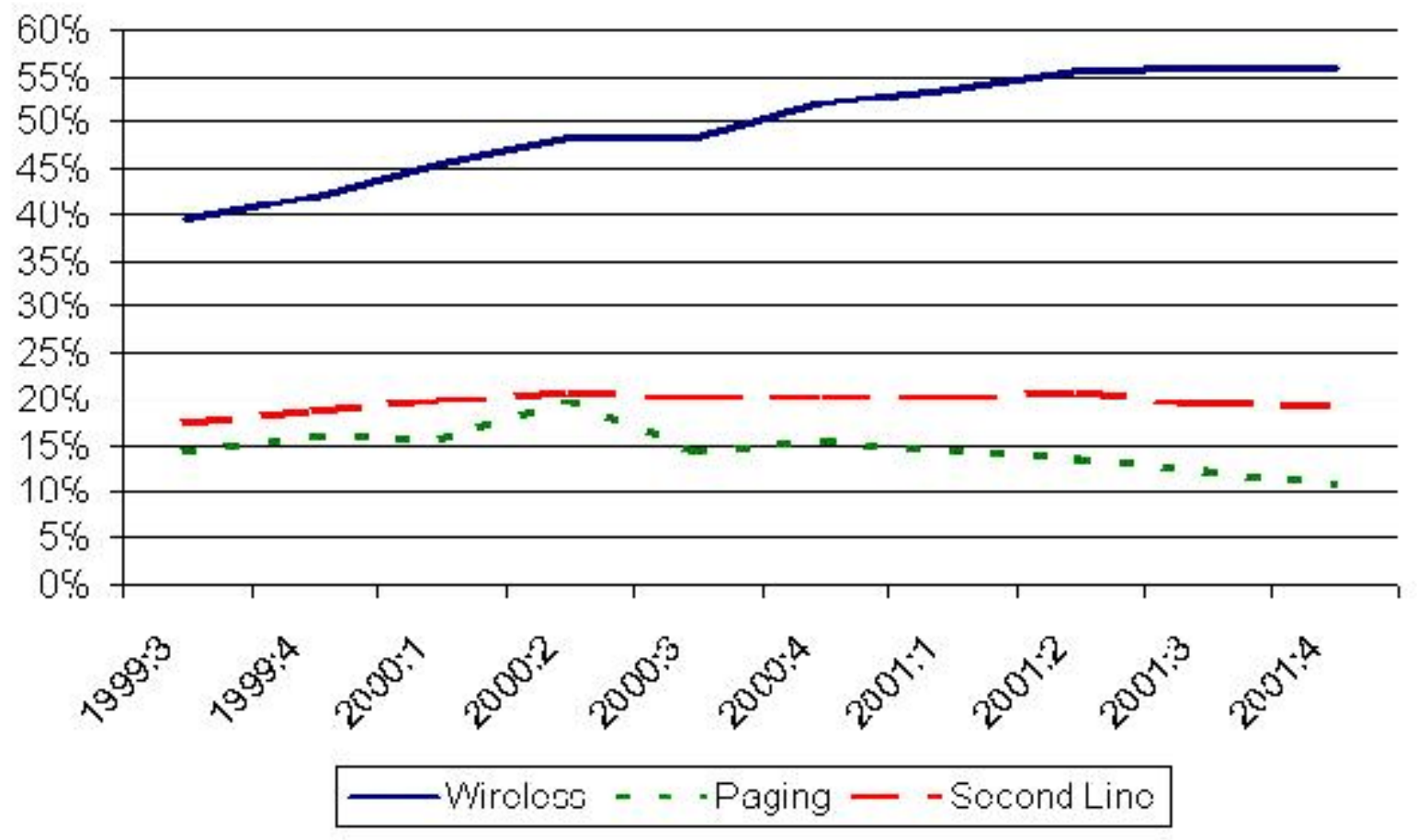


Figure 2

\section{Why Mobile was Purchased}

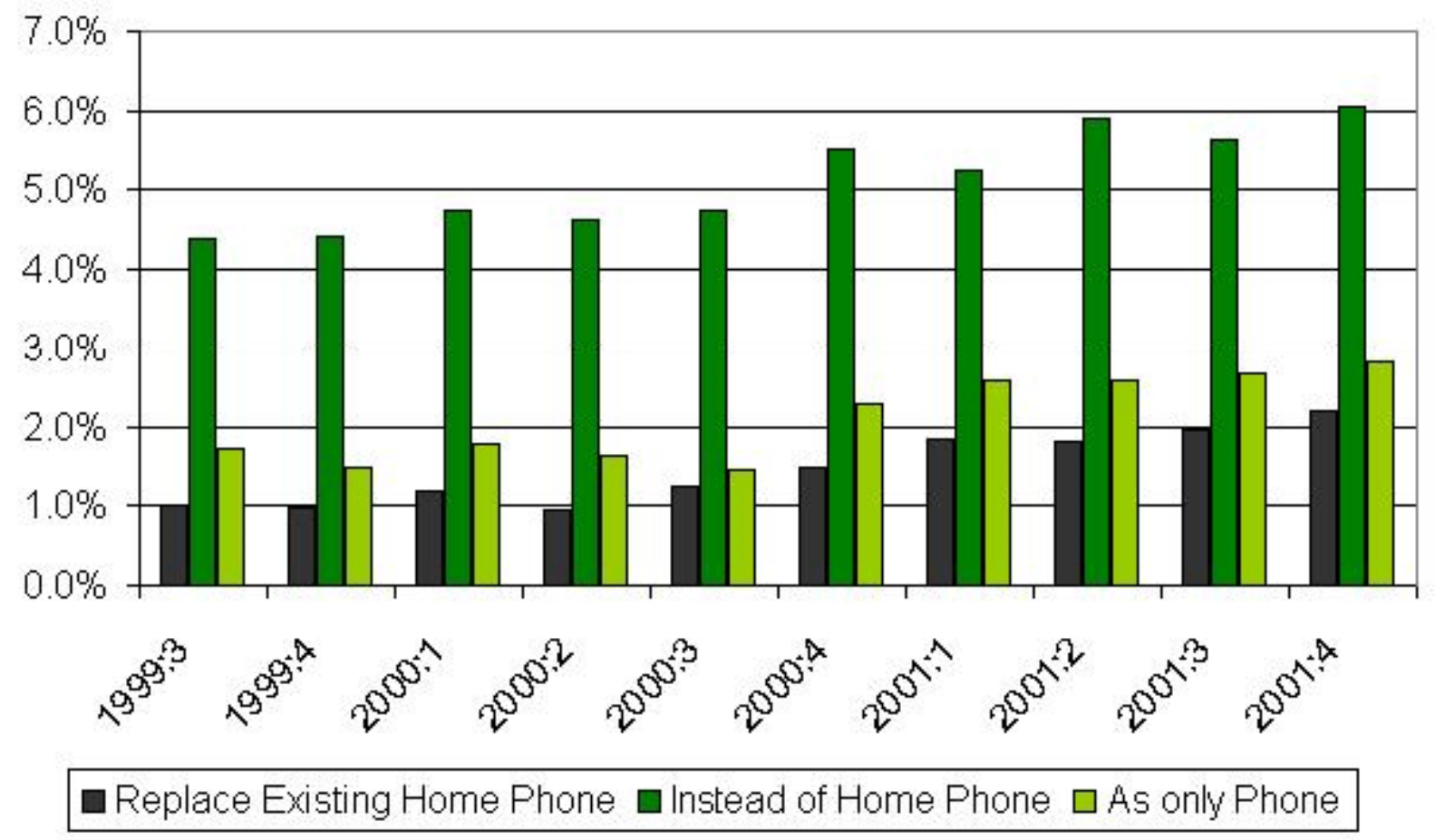




\begin{tabular}{|c|c|c|}
\hline Variable & $\begin{array}{c}\text { Complete } \\
\text { Sample }\end{array}$ & $\begin{array}{l}\text { "Urban" } \\
\text { Sample }\end{array}$ \\
\hline Mobile subscription & $50.6 \%$ & $53.0 \%$ \\
\hline Second fixed-line subscription & $20.0 \%$ & $21.5 \%$ \\
\hline Income $<\$ 25 \mathrm{~K}$ & $26.0 \%$ & $23.6 \%$ \\
\hline Income $\$ 20-\$ 25$ & $8.5 \%$ & $7.9 \%$ \\
\hline Income $\$ 25-\$ 35$ & $13.5 \%$ & $13.3 \%$ \\
\hline Income $\$ 35-\$ 50$ & $17.0 \%$ & $17.2 \%$ \\
\hline Income $\$ 50-\$ 60$ & $8.9 \%$ & $9.3 \%$ \\
\hline Income $\$ 60-\$ 75$ & $9.2 \%$ & $10.1 \%$ \\
\hline Income $>\$ 75$ & $9.2 \%$ & $10.1 \%$ \\
\hline HH Size: single & $24.8 \%$ & $25.2 \%$ \\
\hline HH Size: two & $32.6 \%$ & $32.5 \%$ \\
\hline HH Size: three & $16.9 \%$ & $16.7 \%$ \\
\hline HH Size: four & $15.4 \%$ & $15.5 \%$ \\
\hline HH Size: five or more & $10.3 \%$ & $10.1 \%$ \\
\hline Children Present & $37.4 \%$ & $36.6 \%$ \\
\hline Female Headed & $29.1 \%$ & $29.8 \%$ \\
\hline Married & $55.6 \%$ & $54.9 \%$ \\
\hline Race: White & $87.0 \%$ & $85.8 \%$ \\
\hline Race: Black & $6.7 \%$ & $7.4 \%$ \\
\hline Race: Asian & $3.8 \%$ & $4.2 \%$ \\
\hline Race: Other & $2.4 \%$ & $2.6 \%$ \\
\hline Age: Under 25 & $7.6 \%$ & $7.0 \%$ \\
\hline Age: $25-34$ & $21.4 \%$ & $20.9 \%$ \\
\hline Age: $35-44$ & $24.8 \%$ & $24.9 \%$ \\
\hline Age: $45-54$ & $17.5 \%$ & $18.2 \%$ \\
\hline Age: $55-64$ & $12.1 \%$ & $12.3 \%$ \\
\hline Age: 65 or Over & $16.6 \%$ & $16.7 \%$ \\
\hline Educ HH Head: Grade School & $16.3 \%$ & $14.6 \%$ \\
\hline Educ HH Head: Some High School & $35.3 \%$ & $33.4 \%$ \\
\hline Educ HH Head: HS Graduate & $21.9 \%$ & $23.0 \%$ \\
\hline Educ HH Head: Some College & $17.5 \%$ & $19.0 \%$ \\
\hline Educ HH Head: College Graduate & $9.1 \%$ & $10.0 \%$ \\
\hline Personal Computer & $60.3 \%$ & $62.5 \%$ \\
\hline Internet Access & $49.9 \%$ & $52.7 \%$ \\
\hline Modem & $38.0 \%$ & $40.2 \%$ \\
\hline Pager & $16.0 \%$ & $17.7 \%$ \\
\hline Fax Machine & $12.4 \%$ & $13.5 \%$ \\
\hline Answering Machine & $59.5 \%$ & $60.3 \%$ \\
\hline Frequently Brings Work Home & $22.9 \%$ & $23.8 \%$ \\
\hline Home-based Business & $13.6 \%$ & $13.3 \%$ \\
\hline Telecommutes & $6.8 \%$ & $7.3 \%$ \\
\hline Number of Observations & 327,920 & 230,684 \\
\hline
\end{tabular}




\section{Table 2: VARIABLES AND SOURCES USED IN ESTIMATING MOBILE PRICES}

Variable

Population Density

Land Surface

Topography

Marginal tax rate

Months of operation

Number of firms

HHI

Quality of service

Billing Quarter
Source

U.S. Gazetteer Place and Zipcode Files (1990), zipcode table

USDA Economic Research Services Natural Amenities Index (1970)

State and Local Taxation of Cellular Industry, CTIA (1991)

Cellular Telephone Industry Association, CTIA (1991)

ReQuest Survey, TNS Telecoms (2000-2001)

ReQuest Survey, TNS Telecoms (2000-2001)

ReQuest Survey, TNS Telecoms (2000-2001)

ReQuest Survey, TNS Telecoms (2000-2001)

Table 3: ESTIMATED ACCESS AND USAGE PRICES

\begin{tabular}{lcccc} 
Variable & $\mathbf{2 0 0 0}$ & & 2001 & \\
Mean & Std. Dev. & Mean & Std. Dev. \\
Mobile Access Price & $\$ 23.16$ & $(3.81)$ & $\$ 24.39$ & $(2.32)$ \\
Mobile Usage Price & $\$ 0.11$ & $(0.031)$ & $\$ 0.08$ & $(0.010)$ \\
\hline Number of HHs & 3,677 & & 5,204 & \\
Fixed Access Price & $\$ 32.73$ & $(4.50)$ & $\$ 34.10$ & $(4.51)$ \\
Local Toll Usage Price & $\$ 0.08$ & $(0.044)$ & $\$ 0.08$ & $(0.055)$ \\
\hline Number of HHs & 33,827 & & 32,142 & \\
\hline
\end{tabular}


Table 4: LOGIT PRICE ELASTICITIES FOR MOBILE ACCESS

\begin{tabular}{lcc} 
Price Variable & $\mathbf{2 0 0 0}$ & $\mathbf{2 0 0 1}$ \\
\hline Mobile Access & $-0.43^{*}$ & $-0.43^{*}$ \\
Mobile Usage & $-0.17^{*}$ & 0.04 \\
Fixed Access & $0.18^{*}$ & $0.13^{*}$ \\
Local Toll Usage & 0.00 & 0.01 \\
\hline Number of HHs & 95,174 & 96,000 \\
\hline $\begin{array}{l}\text { NOTE: Elasticities are calculated as averages of household elasticities. } \\
\text { significant at the } 1 \% \text { level }\end{array}$ & \multicolumn{3}{l}{} \\
\hline
\end{tabular}

Table 7: LOGIT PRICE ELASTICITIES FOR SECOND FIXED LINE ACCESS

\begin{tabular}{lcc}
\hline Price Variable & $\mathbf{2 0 0 0}$ & $\mathbf{2 0 0 1}$ \\
\hline Mobile Access & 0.15 & 0.25 \\
Mobile Usage & 0.11 & -0.03 \\
Fixed Access & $-0.68^{*}$ & $-0.62^{*}$ \\
Local Toll Usage & -0.01 & $-0.03^{*}$ \\
\hline Number of HHs & 92,126 & 94,093 \\
\hline NOTE: Elasticities are calculated as averages of household elasticities. & \\
significant at the 1\% level.
\end{tabular}


Table 6: PREDICTED EFFECTS OF VARIOUS NON-PRICE FACTORS

\begin{tabular}{|c|c|c|c|c|c|c|c|c|}
\hline & \multicolumn{4}{|c|}{ Mobile } & \multicolumn{4}{|c|}{ Second Fixed } \\
\hline & \multicolumn{2}{|c|}{2000} & \multicolumn{2}{|c|}{2001} & \multicolumn{2}{|c|}{2000} & \multicolumn{2}{|c|}{2001} \\
\hline Actual subscription rate & \multicolumn{2}{|c|}{$44.8 \%$} & \multicolumn{2}{|c|}{$52.2 \%$} & \multicolumn{2}{|c|}{$18.2 \%$} & \multicolumn{2}{|c|}{$18.0 \%$} \\
\hline Income $<\$ 20 \mathrm{~K}$ & \multicolumn{2}{|c|}{$28.9 \%$} & \multicolumn{2}{|c|}{$39.1 \%$} & \multicolumn{2}{|c|}{$12.9 \%$} & \multicolumn{2}{|c|}{$12.1 \%$} \\
\hline Income $\$ 20 \mathrm{~K}-\$ 25 \mathrm{~K}$ & \multicolumn{2}{|c|}{$38.3 \%$} & \multicolumn{2}{|c|}{$48.2 \%$} & \multicolumn{2}{|c|}{$12.6 \%$} & \multicolumn{2}{|c|}{$12.9 \%$} \\
\hline Income $\$ 25 \mathrm{~K}-\$ 35 \mathrm{~K}$ & \multicolumn{2}{|c|}{$43.8 \%$} & \multicolumn{2}{|c|}{$53.3 \%$} & \multicolumn{2}{|c|}{$12.9 \%$} & \multicolumn{2}{|c|}{$12.6 \%$} \\
\hline Income $\$ 35 \mathrm{~K}-\$ 50 \mathrm{~K}$ & \multicolumn{2}{|c|}{$51.0 \%$} & \multicolumn{2}{|c|}{$60.4 \%$} & \multicolumn{2}{|c|}{$14.4 \%$} & \multicolumn{2}{|c|}{$14.1 \%$} \\
\hline Income $\$ 50 \mathrm{~K}-\$ 60 \mathrm{~K}$ & \multicolumn{2}{|c|}{$58.5 \%$} & & $3 \%$ & & $.3 \%$ & & $4 \%$ \\
\hline Income $\$ 60 \mathrm{~K}-\$ 100 \mathrm{~K}$ & & $.0 \%$ & & $.5 \%$ & & $.9 \%$ & & $3 \%$ \\
\hline Income $>\$ 100 \mathrm{~K}$ & & $2 \%$ & & $3 \%$ & & $6 \%$ & & $3 \%$ \\
\hline Income Unknown & & $1 \%$ & & $3 \%$ & & $.5 \%$ & & $6 \%$ \\
\hline Age: 24 or Under & & $9 \%$ & & $8 \%$ & & $.4 \%$ & & $1 \%$ \\
\hline Age: $25-34$ & & $.5 \%$ & & $4 \%$ & & $6 \%$ & & $6 \%$ \\
\hline Age: $35-44$ & & $8 \%$ & & $9 \%$ & & $.2 \%$ & & $5 \%$ \\
\hline Age: $45-54$ & & $9 \%$ & & $1 \%$ & & $.2 \%$ & & $8 \%$ \\
\hline Age: $55-64$ & & $.0 \%$ & & $8 \%$ & & $.0 \%$ & & $2 \%$ \\
\hline Age: 65 or Over & & $4 \%$ & & $.7 \%$ & & $.0 \%$ & & $2 \%$ \\
\hline HH Size: one & & $8 \%$ & & $3 \%$ & & $7 \%$ & & $7 \%$ \\
\hline HH Size: two & & $9 \%$ & & $.7 \%$ & & $9 \%$ & & $6 \%$ \\
\hline HH Size: three & & $1 \%$ & & $3 \%$ & & $0 \%$ & & $3 \%$ \\
\hline HH Size: four & & $3 \%$ & & $8 \%$ & & $.7 \%$ & & $3 \%$ \\
\hline HH Size: five or more & & $.7 \%$ & & $8 \%$ & & $6 \%$ & & $9 \%$ \\
\hline & No & Yes & No & Yes & No & Yes & No & Yes \\
\hline Female Head & $46.0 \%$ & $57.1 \%$ & $56.3 \%$ & $64.8 \%$ & $15.9 \%$ & $17.4 \%$ & $16.5 \%$ & $18.4 \%$ \\
\hline Black & $48.7 \%$ & $56.6 \%$ & $58.2 \%$ & $66.8 \%$ & $15.9 \%$ & $25.4 \%$ & $15.5 \%$ & $25.1 \%$ \\
\hline Personal Computer & $43.7 \%$ & $52.8 \%$ & $51.8 \%$ & $62.4 \%$ & $13.5 \%$ & $17.5 \%$ & $11.9 \%$ & $17.6 \%$ \\
\hline Internet Access & $44.7 \%$ & $53.5 \%$ & $54.8 \%$ & $61.9 \%$ & $10.9 \%$ & $21.6 \%$ & $11.4 \%$ & $19.3 \%$ \\
\hline Modem & $48.2 \%$ & $50.8 \%$ & $56.7 \%$ & $62.2 \%$ & $14.7 \%$ & $17.8 \%$ & $14.2 \%$ & $17.6 \%$ \\
\hline Pager & $45.4 \%$ & $64.8 \%$ & $56.1 \%$ & $73.0 \%$ & $15.0 \%$ & $20.3 \%$ & $14.8 \%$ & $19.7 \%$ \\
\hline Fax Machine & $47.8 \%$ & $59.0 \%$ & $57.2 \%$ & $68.4 \%$ & $13.7 \%$ & $37.1 \%$ & $13.4 \%$ & $34.0 \%$ \\
\hline Answering Machine & $46.8 \%$ & $50.9 \%$ & $55.6 \%$ & $61.1 \%$ & $16.2 \%$ & $15.8 \%$ & $15.7 \%$ & $15.3 \%$ \\
\hline Freq. Brings Work Home & $47.9 \%$ & $53.8 \%$ & $57.0 \%$ & $64.6 \%$ & $15.7 \%$ & $16.8 \%$ & $15.1 \%$ & $16.7 \%$ \\
\hline Home--based Business & $48.8 \%$ & $52.7 \%$ & $58.3 \%$ & $62.3 \%$ & $15.0 \%$ & $23.0 \%$ & $14.5 \%$ & $22.9 \%$ \\
\hline Telecommutes & $49.1 \%$ & $52.1 \%$ & $58.5 \%$ & $63.5 \%$ & $15.4 \%$ & $24.1 \%$ & $15.0 \%$ & $23.4 \%$ \\
\hline $\begin{array}{l}\text { NOTE: This table reports } \\
\text { for households in each gr } \\
\text { subscription rates were co }\end{array}$ & 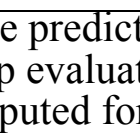 & intor & $T \%$ & ean fo & ig to eac & ch servic & $\begin{array}{l}\text { e in each } \\
\text { s. Actuc }\end{array}$ & year \\
\hline
\end{tabular}


Table 5: Determinants of Wireless Subscription Logit Regression Results

2000

2001

Coef.

Std. Err

Coef.

Std. Err

Price Local Fixed Access

0.002

$-0.014 \quad 0.237$

$0.009^{*} \quad 0.002$

Price Mobile Access

Price Mobile Usage

Income $\$ 20 \mathrm{~K}-\$ 25 \mathrm{~K}$

Income $\$ 25 \mathrm{~K}-\$ 35 \mathrm{~K}$

Income \$35K-\$50K

Income $\$ 50 \mathrm{~K}-\$ 60 \mathrm{~K}$

Income $\$ 60 \mathrm{~K}-\$ 100 \mathrm{~K}$

Income $\$ 100 \mathrm{~K}+$

Income Unknown

HH Size: two

HH Size: three

HH Size: four

HH Size: five or more

Children Present

Female Headed

Married

Race: Black

Race: Asian

Race: Other

Age: 25-34

Age: $35-44$

Age: $45-54$

Age: 55-64

Age: 65 or Over

Some High School

$-0.035^{*} \quad 0.006$

$0.271 \quad 0.172$

$\begin{array}{rr}0.271 * & 0.009 \\ -0.0313 & 0.039\end{array}$

$\begin{array}{llll}0.423 * & 0.031 & 0.371^{*} & 0.030\end{array}$

$\begin{array}{llll}0.650 * & 0.026 & 0.575^{*} & 0.026\end{array}$

$\begin{array}{llll}0.940 * & 0.026 & 0.862 * & 0.025\end{array}$

$\begin{array}{llll}1.241 * & 0.031 & 1.119^{*} & 0.032\end{array}$

$\begin{array}{llll}1.429 * & 0.032 & 1.312 * & 0.033\end{array}$

$\begin{array}{llll}1.663 * & 0.034 & 1.559 * & 0.036\end{array}$

$\begin{array}{llll}1.899 * & 0.039 & 1.727 * & 0.040\end{array}$

$\begin{array}{llll}0.083 * & 0.024 & 0.141 * & 0.024\end{array}$

$\begin{array}{llll}0.091 * & 0.033 & 0.125^{*} & 0.034\end{array}$

$\begin{array}{llll}0.100 * & 0.038 & 0.185^{*} & 0.039\end{array}$

$\begin{array}{llll}0.038 & 0.042 & 0.104 * & 0.042\end{array}$

$\begin{array}{llll}-0.055 & 0.026 & -0.007 & 0.026\end{array}$

$\begin{array}{llll}0.447^{*} & 0.023 & 0.0358^{*} & 0.023 \\ 0.336^{*} & 0.025 & 0.239^{*} & 0.025\end{array}$

$\begin{array}{llll}0.336 * & 0.025 & 0.239 * & 0.025\end{array}$

$\begin{array}{llll}0.317 * & 0.030 & 0.366^{*} & 0.030\end{array}$

$\begin{array}{llll}0.005 & 0.038 & 0.012 & 0.037\end{array}$

$\begin{array}{llll}0.100 & 0.048 & 0.106 & 0.045\end{array}$

$\begin{array}{llll}0.064 & 0.032 & 0.069 & 0.031\end{array}$

$\begin{array}{llll}-0.084^{*} & 0.032 & -0.167^{*} & 0.031\end{array}$

$\begin{array}{llll}-0.161 * & 0.034 & -0.282 * & 0.032\end{array}$

$\begin{array}{llll}-0.195^{*} & 0.036 & -0.418^{*} & 0.035 \\ -0.50 *^{*} & 0.036 & -0.743^{*} & 0.034\end{array}$

$\begin{array}{llll}-0.504 * & 0.036 & -0.743 * & 0.034\end{array}$

HS Graduate

Some College

College Graduate

Personal Computer

Internet Access

Modem

Pager

Fax Machine

Answering Machine

Freq. Brings Work Home

$\begin{array}{llll}0.112 * & 0.024 & 0.040 & 0.023\end{array}$

$\begin{array}{llll}0.179 * & 0.026 & 0.117 * & 0.026\end{array}$

$\begin{array}{llll}0.114 * & 0.028 & 0.018 & 0.029\end{array}$

$\begin{array}{llll}-0.071 & 0.034 & -0.231 * & 0.035\end{array}$

$\begin{array}{llll}0.367 * & 0.025 & 0.435 * & 0.025\end{array}$

$\begin{array}{llll}0.356 * & 0.025 & 0.291 * & 0.024\end{array}$

$\begin{array}{llll}0.103 * & 0.021 & 0.227 * & 0.020\end{array}$

$\begin{array}{llll}0.797 * & 0.020 & 0.748^{*} & 0.024\end{array}$

$\begin{array}{llll}0.451 * & 0.025 & 0.484 * & 0.026\end{array}$

$\begin{array}{llll}0.162 * & 0.016 & 0.230 * & 0.016\end{array}$

Home-based Business

Telecommutes

Avg. Commute

Miles

FIRE Empl.

LEC Avg. Rating

Mobile Avg. Rating

$0.238^{*} \quad 0.020$

$0.155^{*} \quad 0.024$

$0.122 * \quad 0.033$

$0.015^{*} \quad 0.002$

$0.000^{*} \quad 0.000$

$0.000^{*} \quad 0.000$

$-0.082 \quad 0.044$

$\begin{array}{ll}0.440 * & 0.061\end{array}$

$0.318^{*} \quad 0.021$

$0.165^{*} \quad 0.025$

$0.209 * \quad 0.036$

$0.016^{*} \quad 0.002$

$\begin{array}{ll}0.016^{*} & 0.002 \\ 0.000 * & 0.000\end{array}$

Intercept

$-3.558^{*}$

$0.000 * \quad 0.000$

$\begin{array}{ll}-0.001 & 0.043\end{array}$

Observations

Log Likelihood

Pseudo R

95,174
$-53,603$

0.333

0.074

$-1.800 * \quad 0.533$

0.19

$-52,842$

0.20 
Table 8: Determinants of Second Fixed-line Subscription Logit Regression Results 2000

2001

\begin{tabular}{|c|c|c|c|c|}
\hline & Coef. & Std. Err & Coef. & Std. Err \\
\hline Price Local Fixed Access & $-0.027^{*}$ & 0.003 & $-0.023^{*}$ & 0.003 \\
\hline Price Local Toll Usage & -0.218 & 0.304 & $-0.554 *$ & 0.215 \\
\hline Price Mobile Access & 0.008 & 0.008 & 0.013 & 0.011 \\
\hline Price Mobile Usage & 1.347 & 1.014 & -0.448 & 2.328 \\
\hline Income $\$ 20 \mathrm{~K}-\$ 25 \mathrm{~K}$ & -0.021 & 0.047 & 0.068 & 0.047 \\
\hline Income $\$ 25 \mathrm{~K}-\$ 35 \mathrm{~K}$ & 0.001 & 0.039 & 0.044 & 0.039 \\
\hline Income $\$ 35 \mathrm{~K}-\$ 50 \mathrm{~K}$ & $0.130 *$ & 0.036 & $0.174 *$ & 0.036 \\
\hline Income $\$ 50 \mathrm{~K}-\$ 60 \mathrm{~K}$ & $0.277 *$ & 0.041 & $0.350 *$ & 0.041 \\
\hline Income $\$ 60 \mathrm{~K}-\$ 100 \mathrm{~K}$ & $0.452 *$ & 0.040 & $0.483 *$ & 0.040 \\
\hline Income $\$ 100 \mathrm{~K}+$ & $0.624 *$ & 0.040 & $0.670^{*}$ & 0.041 \\
\hline Income Unknown & $1.040 *$ & 0.043 & $1.065^{*}$ & 0.043 \\
\hline HH Size: two & $0.406^{*}$ & 0.033 & $0.377^{*}$ & 0.033 \\
\hline HH Size: three & $0.843^{*}$ & 0.041 & $0.794 *$ & 0.041 \\
\hline HH Size: four & $1.059 *$ & 0.046 & $0.981 *$ & 0.046 \\
\hline HH Size: five or more & $1.264 *$ & 0.050 & $1.178^{*}$ & 0.049 \\
\hline Children Present & $-0.339 *$ & 0.030 & $-0.290 *$ & 0.030 \\
\hline Female Headed & $0.106^{*}$ & 0.031 & $0.130^{*}$ & 0.031 \\
\hline Married & $-0.166^{*}$ & 0.032 & $-0.139 *$ & 0.032 \\
\hline Race: Black & $0.587^{*}$ & 0.036 & $0.602 *$ & 0.035 \\
\hline Race: Asian & 0.019 & 0.046 & -0.010 & 0.045 \\
\hline Race: Other & $0.188^{*}$ & 0.061 & 0.066 & 0.059 \\
\hline Age: $25-34$ & $-0.162 *$ & 0.045 & $-0.146^{*}$ & 0.044 \\
\hline Age: $35-44$ & $0.225^{*}$ & 0.045 & $0.288^{*}$ & 0.043 \\
\hline Age: $45-54$ & $0.495^{*}$ & 0.045 & $0.588^{*}$ & 0.044 \\
\hline Age: $55-64$ & $0.481 *$ & 0.049 & $0.614 *$ & 0.048 \\
\hline Age: 65 or Over & $0.208^{*}$ & 0.052 & $0.418^{*}$ & 0.050 \\
\hline Some High School & $-0.091 *$ & 0.033 & -0.023 & 0.032 \\
\hline HS Graduate & $-0.115^{*}$ & 0.035 & -0.084 & 0.034 \\
\hline Some College & $-0.199 *$ & 0.037 & $-0.176^{*}$ & 0.036 \\
\hline College Graduate & $-0.305 *$ & 0.042 & $-0.231 *$ & 0.041 \\
\hline Personal Computer & $0.312 *$ & 0.037 & $0.459 *$ & 0.037 \\
\hline Internet Access & $0.812 *$ & 0.033 & $0.618 *$ & 0.032 \\
\hline Modem & $0.227 *$ & 0.025 & $0.253 *$ & 0.022 \\
\hline Pager & $0.370^{*}$ & 0.022 & $0.344 *$ & 0.024 \\
\hline Fax Machine & $1.313^{*}$ & 0.024 & $1.206^{*}$ & 0.023 \\
\hline Answering Machine & -0.026 & 0.020 & -0.030 & 0.020 \\
\hline Freq. Brings Work Home & $0.085^{*}$ & 0.022 & $0.117 *$ & 0.022 \\
\hline Home-based Business & $0.528 *$ & 0.025 & $0.556^{*}$ & 0.024 \\
\hline Telecommutes & $0.558 *$ & 0.032 & $0.548 *$ & 0.031 \\
\hline Avg. Commute & $0.032 *$ & 0.003 & $0.029 *$ & 0.003 \\
\hline Miles & 0.000 & 0.000 & 0.000 & 0.000 \\
\hline FIRE Empl. & 0.000 & 0.000 & 0.000 & 0.000 \\
\hline LEC Avg. Rating & -0.063 & 0.056 & $-0.196 *$ & 0.054 \\
\hline Mobile Avg. Rating & $0.404 *$ & 0.082 & $0.419^{*}$ & 0.096 \\
\hline Intercept & $-5.079 *$ & 0.430 & $-4.923 *$ & 0.678 \\
\hline Observations & \multicolumn{2}{|c|}{92,126} & \\
\hline Log Likelihood & \multirow{2}{*}{\multicolumn{2}{|c|}{$-37,331$}} & \multirow{2}{*}{\multicolumn{2}{|c|}{$-38,211$}} \\
\hline Pseudo $\mathrm{R}^{2}$ & & & & \\
\hline
\end{tabular}

